\title{
Evaluation of the effects of pregabalin on chondrocyte proliferation and CHAD, HIF-1 $\alpha$, and COL2A1 gene expression
}

\author{
Duygu Yasar Sirin ${ }^{1}$, Numan Karaarslan ${ }^{2}$
}

\begin{abstract}
${ }^{1}$ Department of Molecular Biology and Genetics, Faculty of Arts and Sciences, Namik Kemal University, Tekirdag, Turkey

2Department of Neurosurgery, School of Medicine, Namik Kemal University, Tekirdag, Turkey
\end{abstract}

Submitted: 25 November 2017

Accepted: 3 January 2018

Arch Med Sci 2018; 14, 6: 1340-1347

DOI: https://doi.org/10.5114/aoms.2018.73134

Copyright $\odot 2018$ Termedia \& Banach

\section{Abstract}

Introduction: The aim of the present study is to investigate the effects of pregabalin (PGB) on chondrocyte proliferation and collagen type II (COL2A1), hypoxia-inducible factor $1-\alpha(H I F-1 \alpha)$, and chondroadherin (CHAD) gene expression in osteoarthritic chondrocytes.

Material and methods: Standard primary chondrocyte cultures were prepared using osteochondral tissues that were surgically obtained from 6 patients with gonarthrosis. Cell morphology was evaluated using an inverted microscope, and cell death and proliferation were determined through MTT analysis, which was confirmed by AO/PI staining and statistically evaluated. The expression levels of CHAD, COL2A1, and HIF-1 $\alpha$ genes were assessed using gene-specific TaqMan Gene Expression Assays.

Results: MTT analyses showed that PGB administration did not have a negative or toxic effect on cell viability and proliferation in cultured chondrocytes $(p<0.001)$, but in our morphological evaluation extracellular matrix development was observed to be weaker in cultures treated with PGB. After $24 \mathrm{~h}$ of treatment, COL2A1, HIF- $1 \alpha$, and CHAD gene expression decreased in the groups to which PGB was applied compared to gene expression before the experiment (at $0 \mathrm{~h}$ ); at $48 \mathrm{~h}, \mathrm{CHAD}$ and HIF-1 $\alpha$ expression increased to the same level as the control group, but the expression of COL2A1 continued to decrease.

Conclusions: Further studies need to be conducted with more participants to prove that there is a negative correlation between extracellular matrix formation and PGB administration. Our preliminary data show that even at low doses and over short-term administration, PGB may affect chondrocyte cells at the gene-expression level.

Key words: CHAD, COL2A1, HIF-1 $\alpha$, osteoarthritic chondrocytes, pregabalin.

\section{Introduction}

The treatment of joint-related diseases, such as osteoarthritis, often involves the use of specialized drugs, including pregabalin (PGB), which, nevertheless, can lead to severe side effects when used in systemic therapies. Even though PGB has been used to treat such diseases for many years, preclinical and clinical studies are still being conducted because of its adverse side effects. Pregabalin is an (S)-3-isobutyl- $\gamma$-aminobutyric

\author{
Corresponding authors: \\ Duygu Yasar Sirin \\ Assist. Prof. Ph.D \\ Department of Molecular \\ Biology and Genetics \\ Faculty of Arts and Sciences \\ Namik Kemal University \\ 59100 Tekirdag, Turkey \\ Phone +9028 22505000 \\ Fax: +90 2825099900 \\ E-mail: dysirin@nku.edu.tr \\ Numan Karaarslan \\ E-mail: numikara@yahoo.com
}


acid (GABA) analog that has an analgesic effect independent from GABA receptors, and it does not alter GABA uptake or degradation [1].

As a calcium (Ca) channel ligand, PGB binds more strongly to the alpha-2-delta $(\alpha-2-\delta)$ subunit of voltage-dependent $\mathrm{Ca}$ channels than its pharmaceutical alternative, gabapentin, which is used in therapy $[2,3]$. By stimulating Ca release from synapses, PGB decreases the release of neurotransmitters such as glutamate and norepinephrine [2]. Pregabalin is used in many fields of medicine, including orthopedics, to relieve postoperative peripheral neuropathic pain [4-7].

Despite its widespread use, several studies have reported side effects and/or adverse effects of PGB, such as dizziness, unconsciousness, decreased sexual desire, hypersensitivity to environmental stimuli, insomnia, loss of one's sense of place and time, ataxia, and tremors [8, 9]. There are also reports in the literature suggesting that PGB does not even have an analgesic effect [10].

Like many other medicines, PGB accumulates in many tissues, including synovial fluid. At the joint surface, synovial fluid supplies cartilage tissue that is lacking blood or lymph circulation and neuronal tissue. Therefore, chondrocytes on the surface of cartilage are exposed to drugs that accumulate in synovial fluid over a long period [11-18]. To our knowledge, there are no studies in the literature investigating the effects of PGB on chondrocyte cells or cartilage tissue and extracellular matrix structure.

In our study, we investigated the effects of pregabalin on collagen type II (COL2A1), hypoxia-inducible factor-1 $\alpha$ (HIF-1 $\alpha)$ and chondroadherin $(C H A D)$ gene expression in cultured chondrocyte cells. COL2A1 is a marker for anabolism in cartilage tissue [19]. In addition, COL2A1 is an important cartilage-specific matrix protein, and COL2A 1 expression is regulated by transcription factors, such as SRY-related HMG-box (SOX9) and transforming growth factor- $\beta$. An increase of $\operatorname{COL} 2 A 1$ gene expression leads to induction of extracellular matrix production [20].

An HIF-1 transcription complex composed of HIF- $1 \alpha$ and HIF- $1 \beta$ subunits regulates the transcription of a wide range of genes involved in glucose metabolism, angiogenesis, and cell survival $[21,22]$. Hormones, growth factors, and hypoxic environments induce the translocation of HIF-1 to the nucleus of the cell. Further, HIF-1 associates with its subunit and forms an active HIF-1 transcription factor to regulate the expression of its target genes [21, 22].

CHAD is a non-canonical class IV small leucine-rich proteoglycan (SLRP) that binds to integrin, cell surface proteoglycans, and COL2A1. CHAD mediates signaling between chondrocytes and the extracellular matrix and plays a role in regulating cartilage homeostasis. Hence, it is important to study these genes and proteins in research on the treatment of joint-related diseases [23].

In this preliminary study, we sought to answer the question whether the treatment of cartilage tissue should be reduced or prolonged when treating patients to relieve post-operative peripheral neuropathic or osteoarthritic pain.

\section{Material and methods}

The study was carried out with the approval of the Local Ethics Board (Namik Kemal University, 2017/41/04/01). Informed consent was obtained from patients attending the Neurosurgery Clinic for use of their cells in the study.

To enhance reliability, the researchers were blinded; they did not know which groups had received PGB, and the content of the drug(s) they applied to the culture was concealed from them via an encoded system. Furthermore, all experiments were repeated at least three times. To minimize measurement errors, the same types of analyses were performed by the same researchers.

\section{Selection criteria for the participants}

Patients with a known drug allergy, including a PGB allergy; patients diagnosed with Parkinson's disease who had received treatment with monoamine oxidase inhibitors, such as rasagiline, selegiline, and moclobemide, in the last 14 days; and patients undergoing antidepressant treatment who were diagnosed with malignancy were not included in the study [12]. The average age of the 6 patients who participated in the study was $64.45 \pm 3.12$ (mean \pm standard deviation; $n=6$ ). Patients who did not respond to conservative medical treatment and had large osteophytes, graded using the Kellgren-Lawrence Radiological Grading Scale (stage IV), were selected [24].

\section{Study design and the in vitro experimental setup}

Standard primary chondrocyte cultures were prepared using osteochondral tissues that were surgically obtained from the six participants. Primary chondrocyte cultures in which PGB was not applied were used as the control group. Before $(0 \mathrm{~h})$ and after PGB application (24 and $48 \mathrm{~h}$ ), chondrocyte cultures were monitored using an inverted microscope, while cell proliferation and viability were analyzed using 3-(4,5-dimethylthiazol-2-yl)-2,5-diphenyltetrazolium bromide (MTT) analysis and acridine orange/propidium iodide (AO/PI) staining. COL2A1, HIF-1 $\alpha$, and CHAD gene expression was detected with real-time polymerase chain reaction (RT-PCR) analysis. 


\section{Obtaining the primary chondrocytes}

In patients undergoing total knee arthroplasty, osteochondral tissues were resected from the surfaces of the distal femur and proximal tibia, which were routinely interrupted. Primary chondrocyte cultures were prepared from the resected chondral tissues of intact joint surfaces [12]. Standard procedures were followed for human primer culture [25]. Tissues were transferred to the laboratory in appropriate conditions in culture medium (Dulbecco's Modified Eagle's Medium (DMEM); Cat. \#41965062; Gibco) supplemented with 1\% penicillin-streptomycin (PS; Cat. \#15140122, Gibco), 15\% fetal bovine serum (FBS; Cat. \#10082147), and 1\% L-glutamine (Cat. \#25030081, Gibco). Osteochondral tissue samples were irrigated with $0.9 \%$ isotonic sodium chloride solution in a laminar flow cabinet until separated from red blood cells. Tissues were dissected, washed in Hank's balanced salt solution (HBSS 1X; Cat. \#14025, Gibco), and transferred to Falcon tubes. Collagenase type II enzymes (0.375 mg; Cat. \#17101015, Gibco) that were dissolved in complete medium were added to the solution and incubated in 5\% $\mathrm{CO}_{2}$ at $37^{\circ} \mathrm{C}$ overnight. Then, the samples were centrifuged at 1,200 rpm for $10 \mathrm{~min}$. The cell pellets were resuspended in cell culture medium, transferred to T75 flasks, and incubated to obtain primary cell cultures [25].

After primary monolayer chondrocyte cultures were obtained, the cultures were trypsinized, and viable cells were counted by trypan blue staining. Obtained cell suspensions were seeded as follows: $1.4 \times 10^{4}$ cells per well to 96 -well plates for MTT analysis, $3.4 \times 10^{4}$ cells per well to 24 -well plates for AO/PI analysis, and $4.4 \times 10^{6}$ cells per dish to $100-\mathrm{mm}$ Petri dishes for RNA isolation. At the end of the 24-hour incubation period, the drug was added to confluent cell cultures to perform the experiments.

\section{Microscopy imaging (inverted and fluorescence)}

An inverted light microscope (Olympus, CKX41) was used to monitor cell cultures, and a fluorescent microscope (Leica; DM 2500) was used for $\mathrm{AO} / \mathrm{PI}$ analysis. Microphotographs of cell structures were obtained before and during PGB applications, and the images were evaluated using a CytoVision capture station imaging program.

\section{Preparation and application of PGB}

The main stock solution of 25- $\mu$ M PGB (Lyrica, Pfizer) was prepared fresh in a flow cabinet and dissolved in DMEM medium. Afterward, the main stock solutions were color coded, which blinded the researchers to the analyses. The final concen- tration of PGB at $25 \mu \mathrm{M}$ was applied to human primary chondrocyte cultures. The drug dosage administered to the cultures was calculated before carrying out the analyses. The concentrations of PGB that were applied to the cultures began at $1 \mu \mathrm{M}$ and proceeded to $25,50,100,250,500$, and $1,000 \mu \mathrm{M}$. It has been previously reported that cell proliferation totally stopped in cultures to which PGB concentrations greater than $25 \mu \mathrm{M}$ were applied. Therefore, the necessary doses of PGB at concentrations allowing proliferation were applied to the cell classes found in the cultures. A final concentration of $25-\mu \mathrm{M}$ PGB was applied to human primary chondrocyte cultures because most pharmaceutical formulations are administered at this concentration, approximately. Prior to conducting the experiments and statistical analysis, the drug was delivered to the researchers in an encoded form. This meant that the researchers were blinded both to the experiments and to the statistical evaluation.

\section{Preparation and application of AO/PI}

$\mathrm{AO} / \mathrm{PI}$ stain was prepared with $10 \mathrm{~g}$ of sodium-ethylenediaminetetraacetic acid, $4 \mathrm{mg}$ of $\mathrm{Pl}$, $50 \mathrm{ml}$ of FBS, $4 \mathrm{mg}$ of $\mathrm{AO}$ (dissolved in $2 \mathrm{ml}$ of $99 \%$ ethanol) and was mixed well; sterile distillated water was added to reach a final volume of $200 \mathrm{ml}$. With the nucleic acid binding dyes of AO and PI, we were able to determine cell viability accurately. As an intercalating dye, AO can permeate both live and dead cells and stain all nucleated cells to generate green fluorescence [26]. Propidium iodide can only enter dead cells, which have poor membrane integrity, and it stains all dead nucleated cells with red fluorescence.

\section{Investigation of the effects of PGB on chondrocyte proliferation with MTT analyses}

A viability test was carried out with a commercial MTT kit (Vybrant MTT Cell Proliferation Assay, Cat. \#V13154, Thermo Fisher Scientific) according to the manufacturer's instructions $[12,25,26]$ MTT analyses were performed before (control group; $0 \mathrm{~h}$ ) and after the PGB solutions were added using an enzyme-linked immunosorbent assay (ELISA) microplate reader (Mindray MR 96 A, PRC).

\section{Gene expression analysis}

Total ribonucleic acid (RNA) was extracted from cultured primary human chondrocytes using a PureLink RNA Mini Kit (Ambion, Cat. \#12183018A) and 2-mercaptoethanol (Thermo Fisher Scientific, Cat. \#31350010). The purified RNA, 50 ng in total, was reverse-transcribed to complementary DNA (cDNA) using a High Ca- 
pacity cDNA Reverse Transcription Kit (Thermo Fisher Scientific, Cat. \#4368814) according to the manufacturer's instructions. The cDNA was subjected to quantitative PCR analysis. Quantitative PCR analyses were performed to analyze the changes in gene expression using TaqMan Gene Expression Assays for CHAD (Hs00154382

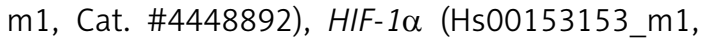
Cat. \#4453320), COL2A1 (Hs00264051_m1, Cat. \#4453320), and the internal control (housekeeping) gene $\beta$-actin (ACTB; Hs99999903_m1, Cat. \#4453320). Each gene was amplified using an RT-PCR reaction mix prepared with $1 \mu \mathrm{l}$ TaqMan Gene Expression Assay, $10 \mu$ of TaqMan Gene Expression Master Mix (Cat. \#4369016), $4 \mu \mathrm{l}$ of cDNA template, and UltraPure DNase/ RNase-Free distilled water (Cat. \#10977035) on MicroAmp Fast Optical 96-well reaction plates (Cat. \#4346906). The Applied Biosystems 7300/7500 RT-PCR system was used with the following reaction protocol: hold at $50^{\circ} \mathrm{C}$ for $2 \mathrm{~min}$, hold at $95^{\circ} \mathrm{C}$ for $10 \mathrm{~min}$, and alternate between $15 \mathrm{~s}$ at $95^{\circ} \mathrm{C}$ and $1 \mathrm{~min}$ at $60^{\circ} \mathrm{C}$ for 40 cycles. The mean value of the three assays was used as a measurement value, and gene expression levels were normalized by the expression of ACTB.

\section{Statistical analysis}

The Minitab R16 program was used for the statistical evaluation. The results were expressed as mean \pm standard deviation. The results were evaluated using an analysis of variance (ANOVA) at $95 \%$ confidence interval to assess whether there were significant differences across groups. The $\alpha$ significance level was set as $<0.05$. When differences across groups were observed, Tukey's honest significant difference (HSD) post-hoc test was used for multiple pairwise comparison.

\section{Results}

\section{Morphological analysis of chondrocyte cultures: inverted microscopy and AO/PI staining}

Morphological evaluation of chondrocyte cultures showed that the application of PGB at various concentrations did not affect cell morphology or proliferation. However, when inverted microscopy images were examined, the number of cells and amount of proliferation were similar in both experimental groups, and extracellular matrix formation was observed to be weaker in the group treated with PGB (Figure 1). AO/PI staining showed that cells from both groups 1 and 2 continued to proliferate within 0-48 $\mathrm{h}$, and no cell death was observed as a result of PGB administration (Figure 2).

\section{Statistical analysis of MTT analysis}

The differences between groups identified by ANOVA and Tukey's HSD test were found to be statistically significant (Tables I and II). Tukey pairwise comparisons showed statistically significant differences among the three groups (A, B, and C; Table II). Cell viability was similar and at its maximum level before the test $(0 \mathrm{~h})$ in the control group and in pregabalin-administered samples. Likewise, cell viability was similar but at its minimum level in the control group at both 24 and $48 \mathrm{~h}$ and in PGB-administered samples at $24 \mathrm{~h}$. In cultures treated with $P G B$, the number of viable cells was found to be greater than that of the control group after $48 \mathrm{~h}$.

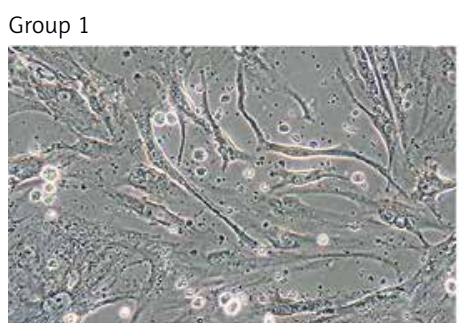

$\mathrm{Oh}$

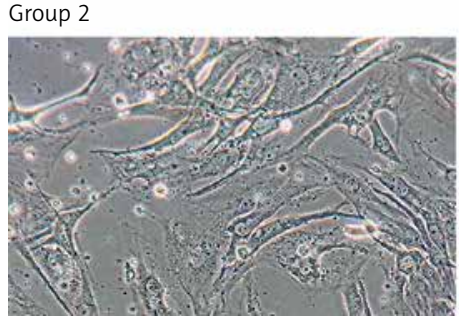

$\mathrm{Oh}$

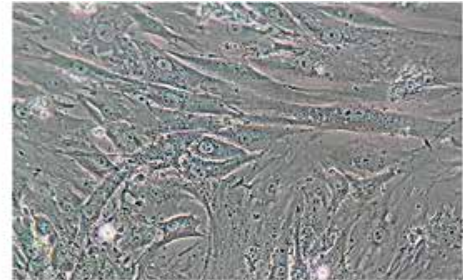

$24 \mathrm{~h}$

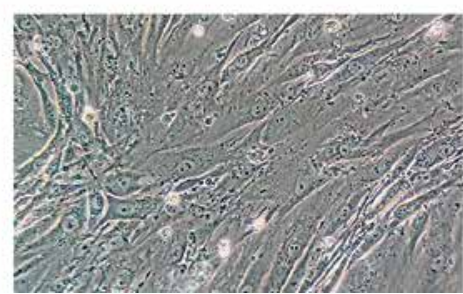

$24 \mathrm{~h}$

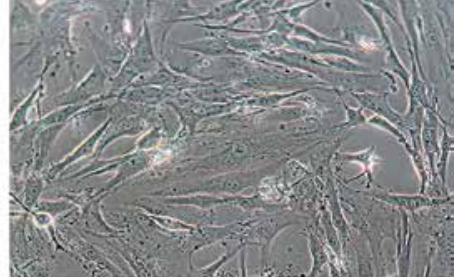

$48 \mathrm{~h}$

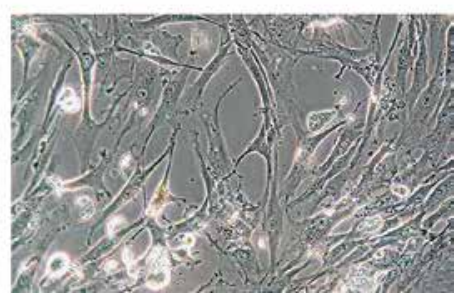

$48 \mathrm{~h}$

Figure 1. Morphological evaluation of chondrocyte cultures

Group 1 - control samples at 0, 24 and 48 h. Group 2-PGB-treated group at 0, 24, and $48 \mathrm{~h}$. 


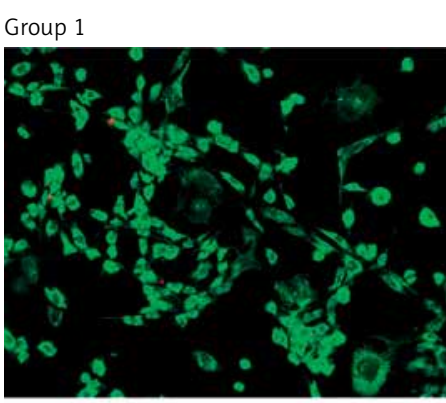

$\mathrm{Oh}$

Group 2

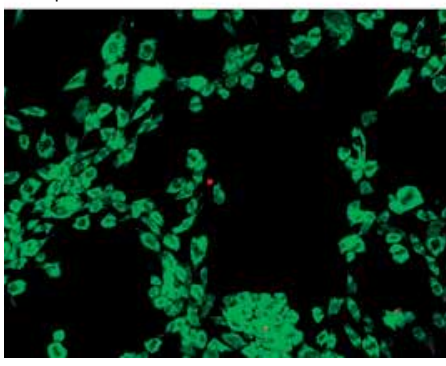

$\mathrm{Oh}$

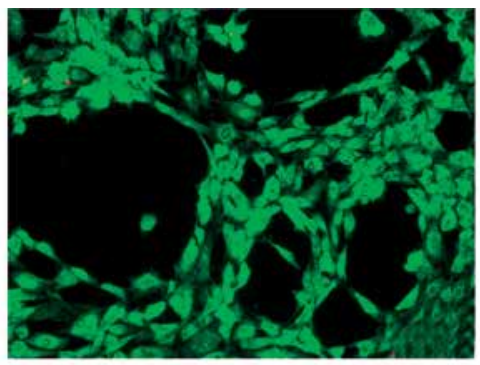

$24 \mathrm{~h}$

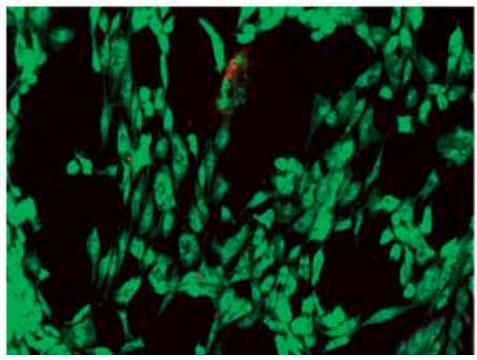

$24 \mathrm{~h}$

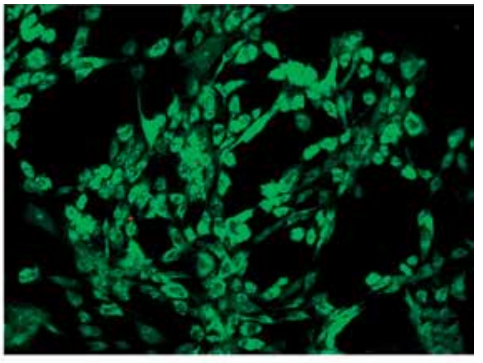

$48 \mathrm{~h}$

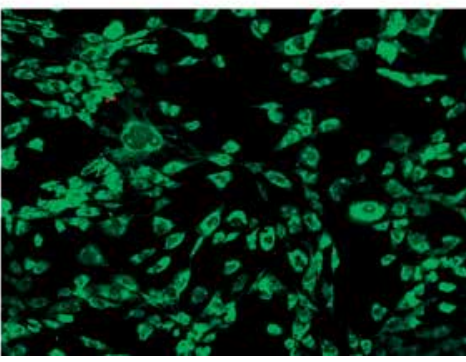

$48 \mathrm{~h}$

Figure 2. AO/PI staining of chondrocyte cultures

Group 1 - control samples at 0, 24, and $48 \mathrm{~h}$. Group 2-PGB-treated group at 24 and $48 \mathrm{~h}$.

Table I. Comparison of the differences between experimental groups: ANOVA of MTT analysis

\begin{tabular}{|lccccc|}
\hline Source & DF & Adj. SS & Adj. MS & F-value & $P_{\text {-value }}^{*}$ \\
\hline Hour & 2 & 0.074235 & 0.037117 & 145.67 & $<0.001$ \\
\hline Application & 1 & 0.003496 & 0.003496 & 13.72 & 13.72 \\
\hline Hour* application & 2 & 0.006992 & 0.003496 & 0.000255 & $<.001$ \\
\hline Error & 54 & 0.013759 & & & \\
\hline Total & 59 & 0.098482 & & & \\
\hline
\end{tabular}

${ }^{\star}$ One-way ANOVA, alpha significance level was set as $<0.05$. The definitions of the symbols are as follows: DF - degrees of freedom, Adj. SS - adjusted sum of squares, Adj. MS - adjusted mean squares.

RT-PCR evaluation of COL2A1, HIF- $1 \alpha$, and $C H A D$ gene expressions

For the RT-PCR evaluation, pre-test cultures without PGB application (group 1, $0 \mathrm{~h}$ ) were used

Table II. Comparison of the differences between experimental groups: Tukey pairwise comparisons of MTT analysis

\begin{tabular}{|lccc|}
\hline Hour* application & $\boldsymbol{N}$ & Mean \pm SD & Grouping* $^{*}$ \\
\hline Control 0 h & 10 & $0.3006 \pm 0.01$ & $\mathrm{~A}$ \\
\hline Pregabalin 0 h & 10 & $0.3006 \pm 0.01$ & $\mathrm{~A}$ \\
\hline Pregabalin 48 h & 10 & $0.2688 \pm 0.01$ & $\mathrm{~B}$ \\
\hline Control 48 h & 10 & $0.2230 \pm 0.03$ & $\mathrm{C}$ \\
\hline Control 24 h & 10 & $0.2156 \pm 0.01$ & $\mathrm{C}$ \\
\hline Pregabalin 24 h & 10 & $0.2156 \pm 0.01$ & $\mathrm{C}$ \\
\hline
\end{tabular}

${ }^{\star}$ Post-hoc Turkey pairwise comparison test. From $A$ to $Z, A$ is the best and $Z$ is the worst. as reference samples. $C O L 2 A 1, H I F-1 \alpha$, and $C H A D$ gene expression levels were accepted as $100 \%$ relative quantification $(R Q ; R Q=1)$ in this group. In the control group and in all the experimental groups, the level of gene expression was normalized by comparison with ACTB expression, which was used as an internal control. At 24 and $48 \mathrm{~h}$, the change in gene expression was calculated as RQ, or, in other words, fold. The RQ values obtained from all experimental groups are presented in Figure 3.

In the control group, CHAD expression increased 1.9-fold and COL2A1 expression increased 3.3-fold at $24 \mathrm{~h}$, but it was observed that the HIF-1 $\alpha$ expression did not change. However, at $48 \mathrm{~h}$, the expression of all three genes was reduced, especially that of $C O L 2 A 1(R Q=0.7)$. In the experimental group treated with PGB, the expression of all three genes decreased by about $50 \%$ $24 \mathrm{~h}$ after application. In this group, CHAD expres- 
sion increased 1.7 -fold at $48 \mathrm{~h}$ and was greater than the control group. The expression of HIF-1 $\alpha$ $(R Q=0.7)$ at $48 \mathrm{~h}$ also increased from its level at $24 \mathrm{~h}$ and reached the same level as the control group. However, the expression of COL $2 A 1$ continued to decrease (Figure 3).

\section{Discussion}

Pregabalin is a GABA analog that was designed to be an analgesic but blocks the release of $\mathrm{Ca}$ channel-mediated neurotransmitters at the presynaptic area independently from GABA receptors [27]. In the literature, it has been reported that adverse effects or other side effects are common in the majority of cases using PGB. However, no studies have reported the effects of pregabalin on chondrocytes or on the extracellular matrix of cartilaginous tissue in humans. Most of the existing studies are animal experiments, and some have been carried out on specimens obtained from animal tissues.

Boileau et al. [28] investigated the effects of $\alpha-2-\delta$ ligands of voltage-activated $\mathrm{Ca}^{(2+)}$ channels on the structure of cartilaginous tissue in a dog model of osteoarthritis. They administered either $15-90 \mathrm{mg} / \mathrm{kg} /$ day of $\alpha-2-\delta$ ligands or a placebo to the subjects and then obtained femoral conduits and tibial plate samples [28]. Aside from conducting macroscopic and histological examinations, the researchers evaluated the expression of inducible nitric oxide synthase (iNOS) and matrix metalloproteinase (MMP)-1, -3, and -13 with RT-PCR or immunohistochemistry analysis. The results of this study suggest that $\alpha-2-\delta$ ligands do not cause drug toxicity and that a significant reduction in the synthesis of all major mediators plays a role in osteoarthritis [28].

In their research, Jang et al. [29] attribute the reason for neuropathic pain to the inflammation that accompanies peripheral nerve injury. The researchers investigated the effects of GABA analgesics, which are used to relieve such pain, on immunomodulation. In their neuropathic pain model, male BALB/C mice were orally administered (S)-3-(aminomethyl)-5-methylhexanoic acid at a dose of $30 \mathrm{mg} / \mathrm{kg}$, and the cytotoxic activity and splenocyte proliferation of natural killer cells were evaluated [29]. The researchers reported that pregabalin therapy significantly suppresses NK cell activity and splenocyte proliferation [29].

Salat et al. developed a painful diabetic neuropathy (PDN) model in mice, reporting in their study that PGB has no effect on glucose utilization or lipid storage in vitro. Furthermore, they stated that PGB has no cytotoxic effect at concentrations between 1 and $100 \mu \mathrm{M}$ [30]. Additionally, as a result of their animal model experiments, Kim et al. pointed out that non-steroid anti-inflammatory

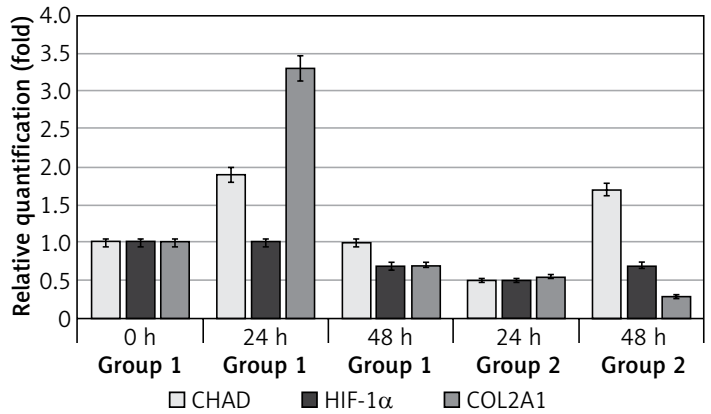

Figure 3. Relative quantification values obtained from experimental groups

Group 1 - control samples 0, 24, and 48 h. Group 2-PGBtreated group at 24 and $48 \mathrm{~h}$.

drug and pregabalin administration did not show an analgesic effect [10].

Many clinicians in different branches prescribe pregabalin for treatment, but the positive or negative effect of PGB on chondrocytes and/or cartilaginous tissues is not recorded in the product monograph or prospectus. In toxicity studies, tissues obtained from animal articular cartilages have been generally evaluated [10, 28, 30].

In this study, we investigated the effect of PGB on chondrocyte viability and proliferation and extracellular matrix components in primary human chondrocyte cultures. In addition, to our knowledge, our study is the first in the literature to determine whether PGB application affects COL2A1, $H I F-1 \alpha$, and CHAD gene expression.

The COL2A1 gene encodes a cartilage-specific extracellular matrix protein synthesized from proliferative chondrocytes that is essential for chondrogenesis [20,31]. In addition, cartilage anabolic processes are marked by the existence of COL $2 A 1$ [19]. Chondrogenesis is regulated by numerous mechanisms, including growth factors such as HIF-1 $\alpha$, a helix-loop-helix transcription factor that is expressed in hypoxic conditions [32, 33]. Consequently, HIF- $1 \alpha$ is accepted as a positive regulator of cartilage development and regeneration [32, 33]. Also, many studies have emphasized the role of HIF-1 $\alpha$ in controlling hypoxia-induced extracellular matrix synthesis in chondrocytes [32-34].

As an SLRP, CHAD mediates signaling between chondrocytes and the extracellular matrix by binding to $\alpha 2 \beta 1$ integrin, cell surface proteoglycans, and type II collagen [23]. It has also been shown that the CHAD gene is upregulated in chondrocyte cultures [35]. Therefore, it has been hypothesized that CHAD plays a critical role in the initiation and progression of osteoarthritis [23].

In our study, morphological and MTT analyses of chondrocyte cultures showed that PGB administration does not have a negative or toxic effect on cell viability and proliferation. Even in cultures treated with $\mathrm{PGB}$, the number of viable cells was 
found to be greater than that of the control group (without PGB) after $48 \mathrm{~h}$. Exclusively, it has been observed that extracellular matrix development is weaker in cultures treated with PGB.

COL2A1, HIF-1 $\alpha$, and CHAD gene expression was evaluated by RT-PCR analysis. It can be argued that the expression of CHAD and COL2A1 increased because of the rapid cell proliferation in the control group from 0 to $24 \mathrm{~h}$. The gene expression levels decreased in these cultures, which became approximately confluent and reached equilibrium at $48 \mathrm{~h}$, as expected. However, in the group to which PGB was applied, the expression of all three genes was much lower than that in the control group at 0 and $24 \mathrm{~h}$. The decrease of the expression of these three genes, which are associated with extracellular matrix development, supports the conclusion of our morphological examinations. In the PGB-applied group, the expression of CHAD and HIF- $1 \alpha$ increased to the same level as that of the control group after $48 \mathrm{~h}$, but the expression of $C O L 2 A 1$ continued to decrease.

Individual differences have a strong impact on drug response; for this reason, an in vitro study is, on its own, not sufficient to determine all the effects of an administered drug. However, because primary cell cultures are heterogeneous and contain all fundamental components of the tissue, the obtained data are more reliable than data from commercial cell lines. Animal model experiments provide essential data on systemic responses, but it is necessary to work with human tissues, particularly when assessing gene expression.

The first limitation of our present study is that no comparison was made between patient and healthy cartilage tissues; it is not ethically possible to obtain cartilage tissue from a healthy person. Second, the primary cell cultures we used were obtained from only 6 patients. Because of this small sample $(n=6)$, RT-PCR data could not be evaluated statistically $[12,25]$. It should also be noted that studies on cytotoxicity gain importance when a new drug is being released to the market thanks to advanced drug technology [36, 37].

In conclusion, further studies, with a greater number of participants, are needed to prove that there is a negative correlation between extracellular matrix formation and PGB administration. Our preliminary data show that even at low doses and over short-term administration, PGB may affect chondrocyte cells at the gene-expression level. Therefore, the results of our study will contribute to the literature by preparing the way for further studies to investigate the action mechanisms of PGB.

\section{Acknowledgments}

We are thankful to Prof. M.D., Ph.D., Hanefi Ozbek, and Ph.D. St. Ibrahim Yilmaz from the Is- tanbul Medipol University School of Medicine, Department of Medical Pharmacology, for determining the exclusion criteria, for editing the article, and for aiding in the statistical evaluation of the data as independent individuals.

\section{Conflict of interest}

The authors declare no conflict of interest.

\section{References}

1. Sills GJ. The mechanisms of action of gabapentin and pregabalin. Curr Opin Pharmacol 2006; 6: 108-13.

2. Gee NS, Brown JP, Dissanayake VU, Offord J, Thurlow R, Woodruff GN. The novel anticonvulsant drug, gabapentin (Neurontin), binds to the alpha2delta subunit of a calcium channel. J Biol Chem 1996; 271: 5768-76.

3. Jones DL, Sorkin LS. Systemic gabapentin and S(+)3-isobutyl-gamma-aminobutyric acid block secondary hyperalgesia. Brain Res 1998; 810: 93-9.

4. Lauria-Horner BA, Pohl RB. Pregabalin: a new anxiolytic. Expert Opin Investig Drugs 2003; 12: 663-72.

5. Dosenovic S, Jelicic Kadic A, Miljanovic M, et al. Interventions for neuropathic pain: an overview of systematic reviews. Anesth Analg 2017; 125: 643-52.

6. Argoff C. Pregabalin is effective in reducing fibromyalgia pain. Evid Based Med 2017; 22: 70-1.

7. Wang D, Zhang K, Han S, Yu L. PainVision(R) apparatus for assessment of efficacy of pulsed radiofrequency combined with pharmacological therapy in the treatment of postherpetic neuralgia and correlations with measurements. Biomed Res Int 2017; 2017: 5670219.

8. Florek-Luszczki M, Zagaja M, Luszczki JJ. Influence of arachidonyl-2'-chloroethylamide, a selective cannabinoid CB1 receptor agonist, on the anticonvulsant and acute side-effect potentials of clobazam, lacosamide, and pregabalin in the maximal electroshock-induced seizure model and chimney test in mice. Fundam Clin Pharmacol 2015; 29: 382-93.

9. Han C, Kuang MJ, Ma JX, Ma XL. Is pregabalin effective and safe in total knee arthroplasty? A PRISMA-compliant meta-analysis of randomized-controlled trials. Medicine (Baltimore) 2017; 96: e6947.

10. Kim JS, Ahmadinia K, Li X, et al. Development of an experimental animal model for lower back pain by percutaneous injury-induced lumbar facet joint osteoarthritis. J Cell Physiol 2015; 230: 2837-47.

11. Leddy HA, Guilak F. Site-specific effects of compression on macromolecular diffusion in articular cartilage. Biophys J 2008; 95: 4890-5.

12. Gumustas SA, Yilmaz I, Isyar M, et al. Assessing the negative impact of phenyl alkanoic acid derivative, a frequently prescribed drug for the suppression of pain and inflammation, on the differentiation and proliferation of chondrocytes. J Orthop Surg Res 2016; 11: 70.

13. Villalvilla A, Gómez R, Largo R, Herrero-Beaumont G. Lipid transport and metabolism in healthy and osteoarthritic cartilage. Int J Mol Sci 2013; 14: 20793-808.

14. Sterner B, Harms M, Wöll S, Weigandt M, Windbergs M, Lehr CM. The effect of polymer size and charge of molecules on permeation through synovial membrane and accumulation in hyaline articular cartilage. Eur J Pharm Biopharm 2016; 101: 126-36.

15. Levick JR. Microvascular architecture and exchange in synovial joints. Microcirculation 1995; 2: 217-33. 
16. Montange D, Berthier F, Leclerc G, et al. Penetration of daptomycin into bone and synovial fluid in joint replacement. Antimicrob Agents Chemother 2014; 58: 3991-6.

17. Aarons $L$. The kinetics of flurbiprofen in synovial fluid. J Pharmacokinet Biopharm 1991; 19: 265-9.

18. Yataba I, Otsuka N, Matsushita I, et al. Plasma pharmacokinetics and synovial concentrations of S-flurbiprofen plaster in humans. Eur J Clin Pharmacol 2016; 72: 53-9.

19. Bauer C, Niculescu-Morzsa E, Jeyakumar V, Kern D, Späth SS, Nehrer S. Chondroprotective effect of highmolecular-weight hyaluronic acid on osteoarthritic chondrocytes in a co-cultivation inflammation model with M1 macrophages. J Inflamm (Lond) 2016; 13: 31.

20. Klangjorhor J, Phitak T, Pruksakorn D, Pothacharoen $P$, Kongtawelert P. Comparison of growth factor adsorbed scaffold and conventional scaffold with growth factor supplemented media for primary human articular chondrocyte 3D culture. BMC Biotechnol 2014; 14: 108.

21. Zelzer E, Mamluk R, Ferrara N, Johnson RS, Schipani E, Olsen BR. VEGFA is necessary for chondrocyte survival during bone development. Development 2004; 131: 2161-71.

22. Charlier E, Relic B, Deroyer C, et al. Insights on molecular mechanisms of chondrocytes death in osteoarthritis. Int J Mol Sci 2016; 17: E2146.

23. Batista MA, Nia HT, Önnerfjord P, et al. Nanomechanical phenotype of chondroadherin-null murine articular cartilage. Matrix Biol 2014; 38: 84-90.

24. Kellgren JH, Lawrence JS. Radiological assessment of rheumatoid arthritis. Ann Rheum Dis 1957; 16: 485-93.

25. Isyar M, Yilmaz I, Yasar SD, Yalcin S, Guler O, Mahirogullari M. A practical way to prepare primer human chondrocyte culture. J Orthop 2016; 13: 162-7.

26. Akyuva Y, Karaarslan N, Yilmaz I, et al. How scaffolds, which are polymeric drug delivery systems allowing controlled release, can be tested in human primary nucleus pulposus and annulus fibrosus cell culture? Merit Res J Med Med Sci 2017; 5: 477-87.

27. Taylor CP, Angelotti T, Fauman E. Pharmacology and mechanism of action of pregabalin: the calcium channel alpha2-delta (alpha2-delta) subunit as a target for antiepileptic drug discovery. Epilepsy Res 2007; 73: 137-50.

28. Boileau C, Martel-Pelletier J, Brunet J, et al. Oral treatment with PD-0200347, an alpha2delta ligand, reduces the development of experimental osteoarthritis by inhibiting metalloproteinases and inducible nitric oxide synthase gene expression and synthesis in cartilage chondrocytes. Arthritis Rheum 2005; 52: 488-500.

29. Jang Y, Song HK, Yeom MY, Jeong DC. The immunomodulatory effect of pregabalin on spleen cells in neuropathic mice. Anesth Analg 2012; 115: 830-6.

30. Salat K, Librowski T, Nawiesniak B, Gluch-Lutwin M. Evaluation of analgesic, antioxidant, cytotoxic and metabolic effects of pregabalin for the use in neuropathic pain. Neurol Res 2013; 35: 948-58.

31. Ushijima T, Okazaki K, Tsushima H, Iwamoto Y. CCAAT/ enhancer-binding protein beta regulates the repression of type II collagen expression during the differentiation from proliferative to hypertrophic chondrocytes. J Biol Chem 2014; 289: 2852-63.

32. Niebler S, Angele P, Kujat R, Bosserhoff AK. Hypoxia-inducible factor 1 is an inductor of transcription factor activating protein 2 epsilon expression during chondrogenic differentiation. Biomed Res Int 2015; 2015 : 380590.

33. Kozhemyakina E, Lassar AB, Zelzer E. A pathway to bone: signaling molecules and transcription factors involved in chondrocyte development and maturation. Development 2015; 142: 817-31.

34. Wang P, Zhang F, He Q, et al. Flavonoid compound icariin activates hypoxia inducible factor-1alpha in chondrocytes and promotes articular cartilage repair. PLoS One 2016; 11: e0148372.

35. Ezura Y, Sekiya I, Koga H, Muneta T, Noda M. Methylation status of $\mathrm{CpG}$ islands in the promoter regions of signature genes during chondrogenesis of human synovium-derived mesenchymal stem cells. Arthritis Rheum 2009; 60: 1416-26.

36. Khan HA, Ibrahim KE. Pattern of neurobehavioral and organ-specific toxicities of beta, beta'-iminodipropionitrile in mice. Arch Med Sci 2015; 11: 1137-44.

37. Fu J. Cx43 expressed on bone marrow stromal cells plays an essential role in multiple myeloma cell survival and drug resistance. Arch Med Sci 2017; 13: 236-45. 